\title{
TRES DÉCADAS DE CAMBIOS EN EL TURISMO MUNDIAL: EL IMPACTO DE LA GLOBALIZACIÓN EN LOS FLUJOS TURÍSTICOS
}

\author{
Francisco García Pascual \\ Departamento de Geografía y Sociología, Universidad de Lleida \\ Cátedra de Turismo de Interior y de Montaña de la Universidad de Lleida y la Diputación de Lleida \\ garcia.pascual@geosoc.udl.cat
}

\section{RESUMEN}

El turismo se ha globalizado y, sin duda, la globalización del capitalismo contemporáneo ha transformado profundamente el modelo turístico. De esta forma, se ha construido un nuevo modelo turismo global coherente con el estadio de desarrollo del capitalismo actual, en el cual conviven formas que predominaban en el sistema turístico mundial que se configuró desde los años 50 a los 80 del siglo XX, con otras formas diferentes de organización, comercialización y consumo de las actividades turísticas y con otras lógicas espaciales de presencia de las actividades turísticas en el territorio. Este nuevo y complejo modelo turístico ha manifestado una notable capacidad de adaptación, basada, sobre todo, en que se desarrolla en su seno una "reinvención permanente" de nuevos productos y la "venta" de nuevos territorios turísticos acompañados de nuevas motivaciones y estructuras, y por dinámicas comerciales y empresariales cada vez más diversas. Todo ello está cambiando los flujos turísticos mundiales.

Palabras clave: Turismo mundial, flujos turísticos, modelos turísticos, globalización.

\section{ABSTRACT}

The tourism has become globalized and, without a doubt, the globalization of contemporary capitalism has profoundly transformed the tourism model. In this way, it has built a new model global tourism consistent with the stage of development of current

Fecha de recepción: diciembre 2015.

Fecha de aceptación: septiembre 2016. 
capitalism, in which living forms which dominated the global tourism system that has been set from the 50's to the 80's of the 20th century, with other different forms of organization, marketing and consumption of tourism and other spatial logics of presence of tourist activities in the territory. This new and complex tourist model has expressed a remarkable capacity of adaptation, based, above all, that develops inside a "permanent reinvention" of new products and the "sale" of new tourist territories accompanied by new motivations and structures, and by increasingly diverse commercial and business dynamics. All of this is changing the global tourist flows.

Keywords: World tourism, tourist flows, tourism models, globalization.

\section{INTRODUCCIÓN}

En el transcurso de las últimas tres décadas el turismo como fenómeno socioeconómico y cultural, y como conjunto de actividades económicas y laborales, está viviendo una profunda transformación. Estos cambios, que afectan a las estructuras turísticas, a las motivaciones por las cuáles se realiza, a los sistemas y empresas de alojamiento y de transporte, a los grupos y clases sociales que participan, a las formas de intermediación turística, y a los territorios que los protagonizan o aquéllos otros que son marginados, han sido de una gran intensidad. Y lo siguen siendo en la actualidad. Toda esta pléyade de transformaciones es el producto fundamentalmente, de un lado, de las dinámicas de las empresas que operan en la multiplicidad de sectores que configuran el turismo hoy en día; de otro lado, de las consecuencias que se derivan de las políticas turísticas locales y nacionales; y, finalmente, y sobre todo, del impacto que sobre las actividades turísticas está teniendo la reestructuración -que no sólo es económica, sino también institucional y sociocultural- que se desarrolla en el capitalismo y que se ha venido en definir como la globalización.

Una globalización, con concreciones y fórmulas muy diversas y hasta contradictorias, que ha sido conducida por las políticas neoliberales, y que ha tenido en la aplicación de los avances tecnológicos y científicos en los procesos productivos, de distribución y de consumo, una de sus consecuencias más significativas. Este proceso está, en términos turísticos, teniendo tres repercusiones clave: la consolidación de nuevas lógicas espaciales del capitalismo y de nuevas formas de articulación de la actividad productiva -que estarían detrás de la emersión de nuevos territorios turísticos, por ejemplo-, el desarrollo tecnológico y su aplicación a los métodos de acceso a la información y de contratación de los viajes turísticos y al abaratamiento de los sistemas de transporte, y la creciente internacionalización de las empresas de los diferentes sectores turísticos.

Asimismo, se debe anotar que, si es indudable el triunfo de capitalismo en la economía internacional, como forma de organización básica del sistema económico mundial, igualmente es evidente el predominio a escala global de las pautas socioculturales de comportamiento -y de consumo- características de las sociedades occidentales más desarrolladas. Uno de los rasgos definitorios de ese conjunto laxo y de límites ambiguos de pautas socioculturales es la conversión del ejercicio del ocio y del turismo en una "necesidad social", en la cual los ciudadanos invierten (consumen) tiempo y recursos para obtener una "satisfacción personal y social". Este hecho es substancial, pues explica en buena medida el por qué las 
nuevas clases medias de países emergentes o de países en desarrollo han asumido el turismo como conformante de su realidad cotidiana y su comportamiento social. El crecimiento del volumen y capacidad de gasto de esas clases medias está siendo un importante motor de expansión del turismo en numerosos territorios y países.

Ahora bien, del mismo modo que la sociedad mundial se "globaliza", homogeneizando sus pautas sociales de comportamiento y consumo, emergen grupos y colectivos sociales que por diversas motivaciones buscan "otras formas de comportamiento y de consumo", iniciándose un camino paralelo de fragmentación de la demanda turística. Ello supone, en términos turísticos, la convivencia de turismos de masas tradicionales consolidados (sol y playa, urbanos o de nieve, por ejemplo), con otros turismos cada vez más diversos en cuanto a sus motivaciones, formas de alojamiento, destinos territoriales y productos y/o atractivos que se ponen en juego para atraer al turista, empresas que los impulsan y forma de acceso de la ciudadanía a través de los medios de comunicación, de internet y de las redes sociales en cualquiera de sus manifestaciones actuales.

En el presente artículo pretendemos, partiendo de estas premisas, ofrecer un bosquejo general del turismo a escala mundial y regional, a partir de valorar e interpretar la evolución durante estas postreras tres décadas de los grandes flujos turísticos que se desarrollan en el mundo. Así como, delimitar sus principales características y vislumbrar aquellos elementos que pueden ayudar a definir las potenciales vías de evolución del turismo en el medio plazo.

\section{GLOBALIZACIÓN Y TURISMO}

Desde la década de los años 80 del siglo XX hasta esta mitad de la segunda década del siglo XXI, han transcurrido unos años que han transformado rápida y profundamente la realidad mundial. Sin duda, ese cúmulo de mutaciones en todos los órdenes ha tenido en la globalización su ariete fundamental, convergiendo en una nueva modernidad (Giddens, 1991). En este sentido, Santos (1996: 69) señalaba que "la globalización constituye el estadio supremo de la internacionalización, la introducción en el sistema-mundo de todos los lugares y de todos los individuos, aunque en diversos grados", mientras que el Banco Mundial (2015), desde postulados ideológicos notablemente diferenciados, indicaba en su página web que la globalización se "relaciona con el hecho de que en los últimos años una parte de la actividad económica del mundo que aumenta en forma vertiginosa parece estar teniendo lugar entre personas que viven en países diferentes (en lugar de en el mismo país)". En todo caso, como nos recordaba Vázquez Baquero (2005: 2) el desarrollo económico mundial se está articulando por el incremento de los flujos económicos y financieros internacionales, al mismo tiempo que por un aumento del intercambio cultural, político e institucional.

A estos hechos debemos unir, según consideramos, de un lado, el papel clave que desempeñan la aplicación intensa y masiva de las nuevas tecnologías de la comunicación y la información y los avances científicos en los diversos procesos de producción, distribución y consumo -provocando un reorganización de las formas de producción que giran hacia el postfordismo y nuevas lógicas espaciales de localización de las actividades productivas-; y, de otro lado, la aceleración de los procesos de movilidad de las personas y concretamente de la fuerza de trabajo -derivándose de ello una reestructuración de la división internacional del trabajo preexistente-. En tanto que Iani (1999) y Adda (2004) destacaban que la globa- 
lización es un proceso que hunde sus raíces en la historia moderna y contemporánea, que ha estado históricamente unido al desarrollo del capitalismo, y lo conceptualizan como un proceso de largo recorrido histórico, repleto de continuidades y rupturas. Un proceso que reconstruye todo un acervo ideológico (Boltanski, Chiapello, 2002; Amin, 2001) que se traduce en un conjunto de medidas políticas que se han venido a definir como neoliberales y que de una u otra forma acaban impregnado las políticas económicas y sociales de la mayor parte de gobiernos. Estos decenios de consolidación de la globalización, como consecuencia de la forma en las que ha evolucionado, ha permitido la emersión de nuevos y dinámicos territorios, la interconexión entre estos y los centros tradicionales de la economía mundial, pero también la fragmentación y la marginación de otros (Bervejillo, 1996; Castells y Himanen, 2014; Stiglitz, 2002; Harvey, 2007; Ibañez et al., 2009).

Estos años han ido acompañados, entre otros hechos, de la caída del bloque soviético, el incremento de las tensiones territoriales que en numerosos casos han llevado a procesos bélicos, una relativa pérdida de peso económico a escala global de América del Norte y de Europa Occidental en beneficio de lo que se ha denominado conjunto de países emergentes (China, Brasil, India, Argentina, México, Indonesia, Rusia, Turquía...), la globalización de las organizaciones terroristas y de sus acciones, la construcción de nuevas alianzas económicas y políticas, los múltiples impactos del cambio climático, y, sobre todo, se ha asistido a una evolución de la economía mundial cuya trayectoria ha dibujado un escenario de profundas crisis económicas (1973 a 1985, de 1991 a 1995, de 2007 a 2015) seguidas de vigorosas fases expansivas, todas ellas acaeciendo con relativa rapidez (1986 a 1990, de 1996 a 2006, de 2015 en adelante). Todo ello ha contribuido a configurar un mundo multipolar, más complejo e inestable (Baylis, Smith, 2005).

Este es el contexto en el cual el turismo se ha convertido en una de las manifestaciones más paradigmáticas de la globalización. En un doble sentido. Por una parte, el turismo como sistema económico, sociolaboral, institucional y cultural de actividades que se conforman alrededor de la producción y consumo del bien turístico, a partir de su naturaleza ha contribuido notablemente al propio proceso de globalización, como así lo han puesto de manifiesto Córdoba y García (2003:117) cuando señalan que "el turismo es un vector de la globalización, porque promueve flujos financieros, de mercancías, de personas y de ideas a nivel planetario". Por otra parte, las lógicas organizativas y locacionales que sustentan la globalización y la reestructuración del capitalismo actual han incidido en la transformación profunda del sistema turístico internacional y de los sistemas turísticos nacionales, regionales y locales, con grados y formas diversas que responden tanto al propio nivel de desarrollo de la formación social de la cual forman parte, como por el impacto de los intereses de las grandes empresas turísticas internacionales. En este sentido, Keller (1996) acertadamente señalaba que la globalización es una megatendencia que ha acabado cambiando la realidad turística internacional. Esta megatendencia se concreta en una serie de elementos que interactúan recíprocamente, y nosotros consideramos que no necesariamente en la misma dirección, sino que a veces contradictoriamente, y que son en buena medida los motores de esos cambios; dichos elementos son para Wahab y Cooper (2001: 6) la calidad, las condiciones de producción, el rol de las autoridades públicas, las estructuras de las corporaciones (las empresas) y las estrategias de precios. A ellos debemos añadir las estructuras laborales y las normas que delimitan los mercados laborales nacionales y locales. 
Estos elementos tienen mucho que ver con la competitividad turística, que se ha erigido en estos años en uno de los aspectos que ayudan a interpretar la evolución que sigue el turismo en el mundo globalizado (Hassan, 2000; Marrero y Santana 2008; Ibáñez Pérez, 2011; Montanari et al., 2013). La dialéctica que se ha establecido entre la competitividad de los productos turísticos, la competitividad de los territorios y lugares turísticos, y la competitividad de las empresas turísticas, explica en última instancia tanto la emersión de nuevos productos o espacios turísticos como la consolidación de los existentes, pero también la marginación de determinados territorios de los grandes flujos turísticos. Asimismo, ha desempeñado un papel esencial la valoración del turismo como un instrumento de desarrollo económico y social de primera magnitud -cuya capacidad de transformación económica se reafirmaba observando las cifras expansivas de viajeros e ingresos del turismo internacional-, lo que ha propiciado que muchas administraciones nacionales, regionales y locales impulsasen planes, programas o actividades turísticas en sus territorios: unas veces directamente $\mathrm{u}$ otras apoyando a las iniciativas privadas locales y/o aquellas que se asientan en capital internacional, o fomentando la llegada masiva y creciente de turistas en unos casos y en otros promoviendo un desarrollo turístico sustentable (López Palomeque, 1999; Vera y Baños 2010; Anthony y Sharplay, 2009; Antón y Duro, 2009; Asheley y Michell, 2010; Muñoz, Fuentes y Fayos-Solà, 2012).

En cierta forma, estos años están forjado un nuevo modelo turismo global concordante con el estadio de desarrollo del capitalismo actual, en el cual conviven formas que predominaban en el sistema turístico mundial que se configuró desde los años 50 a los 80 del siglo $\mathrm{XX}$, con otras formas diferentes de organización, comercialización y consumo de las actividades turísticas y con otras lógicas espaciales de presencia de las actividades turísticas en el territorio. En este sentido, entre sus principales rasgos, Fayos-Solà (2004: 217) identifica tres de fundamentales: “a) la extensión de la demanda turística intra e interregional a nuevos países en el mundo, si bien existen todavía muchos segmentos de población que sólo viajan localmente e incluso son ajenos al turismo; b) la convergencia de comportamientos, gustos y estilos de viajes, si bien ha aumentado la segmentación de tipos de viajes; c) la estandarización y concentración creciente de la oferta turística (alojamiento, transporte, distribución...), si bien han aparecido nuevos agentes especializados". Derivado de ello, podemos hablar de un modelo turístico que se define por la intensa segmentación del mercado de masas turístico que había caracterizado al modelo imperante desde la postguerra mundial (Lichorish y Jenkins, 2000: 267). Igualmente, este modelo turístico, pese al crecimiento importante del número de turistas, sigue mostrando una estrecha relación entre nivel de renta y capacidad de gasto turístico, es decir, que las desigualdades sociales que caracterizan al mundo de hoy en día se reflejan fehacientemente en el acceso y disfrute de las actividades turísticas, de las cuáles una parte de la población sigue excluida.

Así, este nuevo modelo turístico global comprende: por una parte, un conjunto heterogéneo pero jerarquizado de empresas transnacionales, nacionales y locales de alojamiento (cabe aquí destacar el creciente papel del sector inmobiliario y de la construcción en relación al turismo), restauración, transporte, intermediación, difusión y márqueting, y de ocio. De otra, abarca espacialmente la práctica totalidad del planeta pero se construye a nivel local (la dialéctica entre lo global y lo local en el turismo contemporáneo se ha acentuado extraordinariamente), territorios que ponen en el mercado turístico sus recursos 
medioambientales, patrimoniales, culturales y sociales; asimismo, dispone de un entramado institucional y político que le confiere coherencia y lo normativiza y regula, pero que cuenta con una consistencia y capacidad dispar según las sociedades. Y, por último, se sustenta en la extensión a casi todos los países de una determinada construcción social del turismo predominante en las sociedades de los países más desarrollados, que, como ya hemos señalado, ha asumido el turismo en sus diversas formulaciones como una inversión de tiempo y de recursos satisfactoria para el individuo y positiva para el conjunto de la sociedad.

En el campo de juego dibujado por la globalización, el nuevo modelo turístico ha demostrado una notable capacidad de adaptación a las diversas coyunturas. A ello han contribuido dos factores importantes. El primero estriba en el conjunto de políticas nacionales e internacionales que desde ópticas neoliberales han propiciado la liberalización de los mercados de capitales y del comercio de bienes y servicios, lo que ha permitido las inversiones de las multinacionales turísticas en diversos países y los procesos de concentración empresarial de los subsectores de alojamiento, transporte, intermediación y de ocio -lo que sin duda tiene su impacto en el terreno de la competitividad-. En este sentido, ello es posible igualmente por la creciente desregulación de los mercados laborales nacionales y por el aumento de los movimientos migratorios que han ayudado las empresas turísticas a competir por la vía de los precios, gracias a la reducción de los costes salariales. El segundo radica en la capacidad de este modelo turístico de convertir elementos innovadores que "chocan" con los intereses inmediatos del establishment turístico-empresarial, en un elemento más del modelo: el caso más evidente ha sido el de la emersión de las plataformas de intermediación online de alojamientos, restauración y transportes que están cambiando las formas de relación entre las empresas y productos turísticos y los consumidores turísticos. Lo mismo podríamos decir de lo que ha sucedido con nuevos productos turísticos o de nuevas formas de consumo turístico, que han emergido durante estos años.

Sin embargo, como nos recuerdan Keller y Bieger (2001: 1) el turismo, es un conjunto de actividades muy volátiles, que se muestran muy dependientes de hechos y factores naturales, económicos, políticos y socioculturales que las empresas del sector turístico obviamente no controlan. La historia de estas tres décadas muestra claramente el impacto que ha sufrido el mundo turístico ante determinadas catástrofes naturales, las crisis económicas, las tensiones políticas, los problemas sanitarios globales o las amenazas terroristas. Pese a que esta última aseveración es incuestionable, no lo es menos la capacidad del sector de recuperarse, de seguir expansionándose, reconstruyéndose permanentemente para adaptarse con relativa rapidez a los nuevos contextos -si bien ni todos los sectores turísticos, ni todos los productos turísticos, ni todos los territorios turísticos disponen de las mismas condiciones para conseguir el éxito en estos procesos de tensión/adaptación permanentes-.

Esta forma de globalización del turismo ha ido aparejada de significativos cambios en este sector. De entre ellos, podemos destacar cuatro por su relevancia: a) la configuración de una lógica espacial turística compleja, en la que se desarrollan al mismo tiempo procesos de concentración territorial, de diseminación de esta actividad por casi todo el planeta, y de emersión en determinados casos de nuevos espacios turísticos que se consolidan con rapidez y alcanzan una notable dimensión; b) han aparecido o se han reforzado con fuerza nuevas tipologías turísticas más allá del turismo de sol y playa y del de nieve y deportes de invierno, 
como pueden ser el turismo urbano de masas, el turismo rural, el ecológico o medioambiental, el solidario o cooperativo, el de aventura o turismo activo, el turismo gastronómico, el crucerismo, el del comercio urbano tanto de proximidad ligado a pequeñas y medianas urbes como el internacional sustentado en grandes ciudades, el patrimonial y cultural tanto rural como urbano, el de salud, y el de eventos deportivos o musicales, por citar algunos; c) las agencias de viajes han entrado en crisis ante el empuje de nuevas formas de intermediación ligadas a internet y a las tecnologías de la información y la comunicación ${ }^{1}$; y, por último, d) se ha agudizado la tendencia a la concentración empresarial en el sector turístico, destacando el papel de las grandes empresas internacionales ${ }^{2}$, de forma paralela a que algunas de estas empresas han construido su estrategia de competitividad básicamente en contar con precios bajos (low $\operatorname{cost}^{3}$ ), que ha tenido una especial presencia en el sector de los transportes de pasajeros.

1 Primero fueron las propias empresas tradicionales (de forma especial de transporte y las de alojamiento) las que pusieron en marcha canales de venta online de sus productos, después emergieron portales-web que recopilaban información que aparecían en las webs oficiales de las empresas de transporte o alojamiento, para ahora situarse en una posición dominante portales-web que además de ello gestionan millones de opiniones de los viajeros/usuarios condicionando en buena medida la elección final del viajero. En estos últimos años han aparecido también portales-web que recopilan la oferta de alojamiento privado no oficial repartido por diversos lugares del mundo, ajenos a los canales de las grandes cadenas de alojamiento y a la intermediación de las agencias de viaje. Dos ejemplos paradigmáticos podemos indicar al respecto. Por una parte, Booking.com uno de los mayores portales-web de reserva de alojamiento hotelero que dispone de información sobre 718.000 alojamientos ubicados en 83.000 destinos repartidos por 221 países y territorios -concretamente contaría con datos de casi 400.000 hoteles o establecimientos similares, lo que representa el $70 \%$ de la oferta mundial de este tipo de alojamientos-. Por otra, tenemos Tripadvisor un mega portalweb que intermedia tanto con la información de precios y disponibilidad de centenares de miles de alojamientos de todo el mundo, como con las 150 millones opiniones de 500 millones de usuarios activos, o, por ejemplo, supera las 2.000 millones de visitas anuales a su web. Es evidente que, con estos datos, la capacidad de competir con las agencias de viajes tradicionales es rotunda, así como su capacidad de influir en las decisiones de los potenciales consumidores turísticos. Estos datos provienen de las webs de estas dos empresas (www.booking. com y www.tripadvisor.com).

2 En efecto, la concentración es evidente en el mundo turístico. De un lado, las 20 primeras grandes cadenas hoteleras mundiales en el año 2013 disponían de más de 49.000 hoteles y casi 11.000.000 de plazas de alojamiento, el $9 \%$ y el $15 \%$ respectivamente del total mundial (fuente: www.hotelsmag.com y base de datos de plazas en hoteles de la OMT www.unwto.org/statistics/ y www.e-unwto.org/). Como ejemplo, retengamos que la primera gran multinacional de alojamiento la empresa Intercontinental Hotels Group tenía en el año 2013 un total de 4.653 hoteles con 679.000 habitaciones que suponían aproximadamente 1.300 .000 plazas, mientras que en ese mismo año Francia contaba con 1.277.000 plazas hoteleras. De otro, si bien en el mundo se operan casi 200 compañías aéreas internacionales y nacionales que sumaron 3.071 millones de pasajeros, solamente las 20 primeras concentraron el $56 \%$ de los pasajeros transportados en el año 2014 (fuente: http://topairlinesrankings.blogspot.com.es/2014/08/world-top-200passenger-operations.html y http://www.iata.org/publications/pages/wats.aspx).

3 En este sentido, el mundo de las compañías de low cost ha resultado paradigmático. Así, la prensa recogía recientemente que el 49,4\% del volumen de pasajeros transportados por avión en la Unión Europa entre enero y junio del 2015 lo ha sido en compañías áreas de low cost (http://www.abc.es/economia/20150817/abci-viajeroscompanias-lowcost-201508171014.html). La empresa más emblemática es, sin duda en Europa, Ryanair, que ya ocupa la primera posición entre las compañías europeas, por el volumen de pasajeros transportados en territorio comunitario, superando a otras tan emblemáticas como KLM, British Airways, Iberia, Air Italia o Lufthansa. La penetración de este tipo de compañías, y sus implicaciones en facilitar el acceso al transporte aéreo a otros grupos sociales y posibilitar el acceso a lugares no nucleares turísticamente, han sido muy notables y han contribuido decisivamente en cambiar el modelo turístico global. 


\section{CAMBIOS Y PERMANENCIAS EN LOS FLUJOS TURÍSTICOS MUNDIALES}

\section{III.1. Una visión global: el turismo internacional}

Una rápida mirada a la trayectoria seguida por el turismo internacional entre 1980 y 2014, como un primer reflejo de la evolución general del sector turístico mundial, pone de manifiesto una más que notable expansión. El número de turistas internacionales estimados por la OMT en 1980 fue de 278 millones, mientras que en el año 2014 alcanzó los 1.133 millones de personas. Esto supone un promedio de crecimiento anual de un vigoroso 4,3\% durante estos treinta y cuatro años. Es más, la cifra de 1980 equivalía al $6 \%$ de la población mundial, mientras que la del 2014 representaba el 16\% de los habitantes del planeta, manifestando cómo se ha acrecentado la base demográfica y social que ahora participa de las actividades turísticas fuera de su país de residencia habitual.

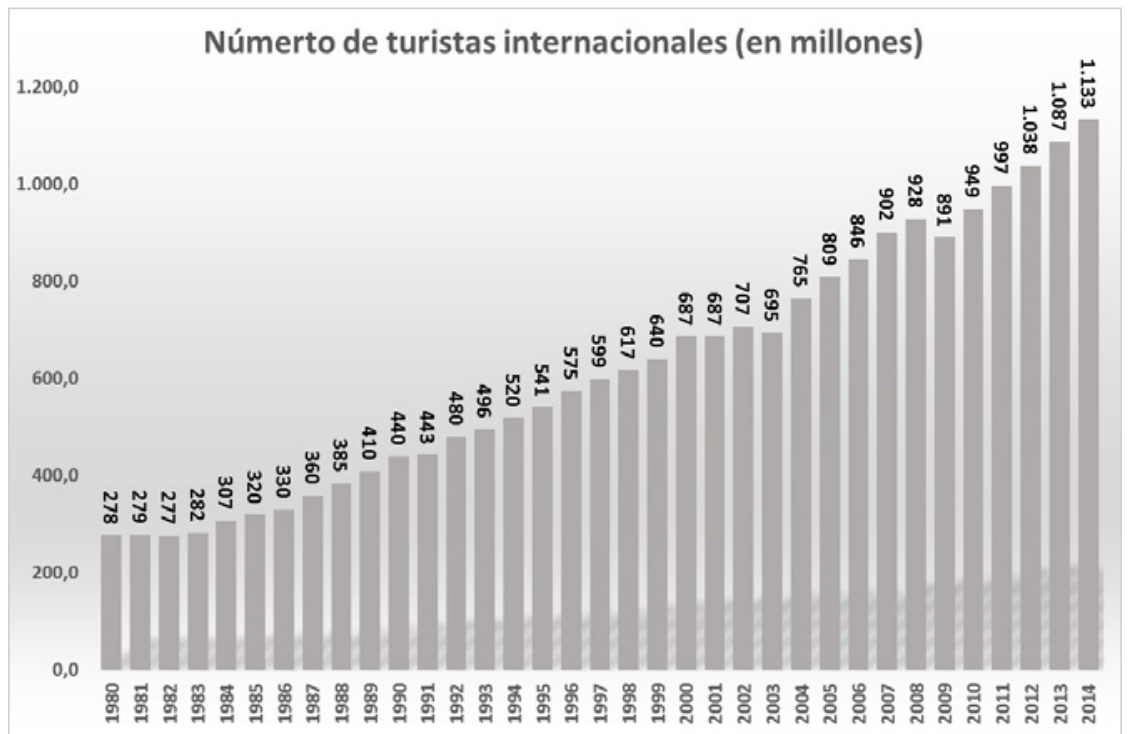

Fuente: elaboración a partir de los datos de la OMT.

Este incremento del flujo turístico mundial se ha traducido en un salto significativo en el volumen de ingresos que de él se obtiene. Efectivamente, si en 1980 los ingresos por turismo internacional fueron de 104.000 millones de \$, en el año 2014 han ascendido a 1.245 .000 de millones de $\$$-cabe tener presente que estas cifras no incluyen el gasto en transporte, que elevaría en unos 200 mil millones la cifra- ${ }^{4}$. En términos nominales esto supone un alza

4 Las últimas cifras publicadas por la OMT (2017) muestran que el número de turistas internacionales ascendió a 1.235 millones, y los ingresos directos sin transporte a 1.220 millones de $\$$ en el año 2016. 
anual media del 7,8\% , aunque si la valoramos en términos reales, en dólares constantes de 2014 y por tanto eliminamos el efecto de los precios implícitos, la progresión sigue siendo muy transcendente: un promedio anual del 4,9\%. En este sentido, debemos comparar esta ratio con el propio devenir de la economía mundial que, entre 1980 y el 2014, haría aumentado a un ritmo medio anual del $2.9 \%^{6}$; lo que, sin duda, demuestra que el turismo, por lo menos los flujos turísticos internacionales y los ingresos que generan, han manifestado un dinamismo superior al de la economía global.

\section{Gráfico 2}

EVOLUCIÓN DE LOS INGRESOS DEL TURISMO INTERNACIONALES 1980 A 2014

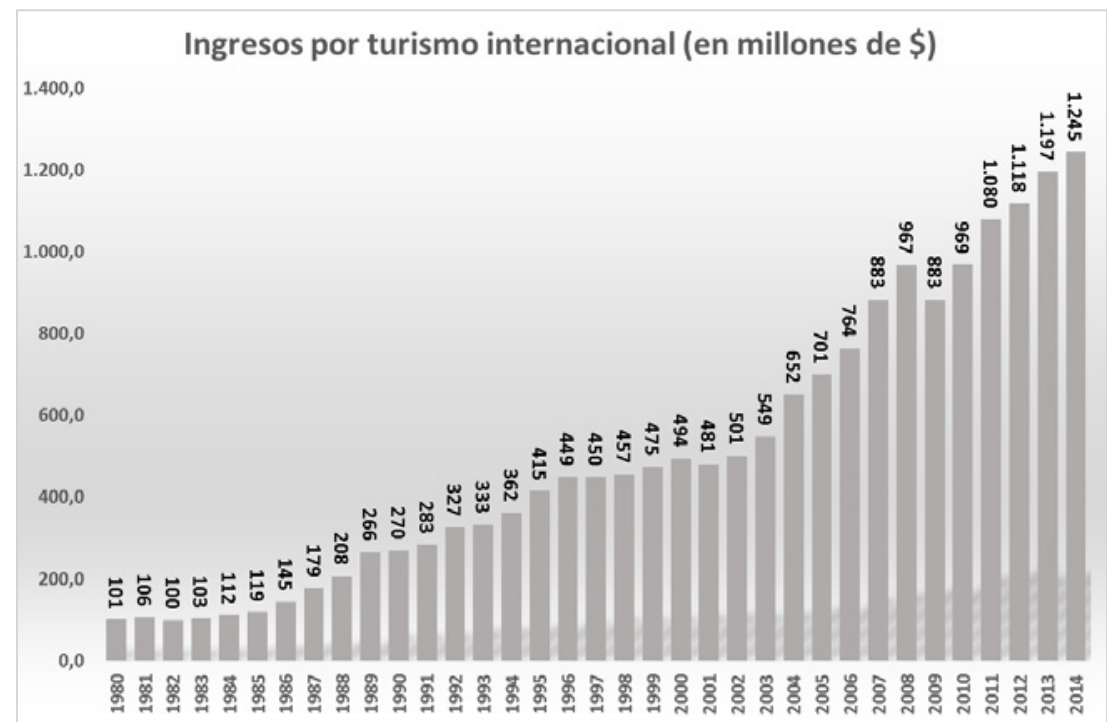

Fuente: elaboración a partir de los datos de la OMT.

Si observamos las dos dinámicas, la seguida por el volumen de turistas y la dibujada por los ingresos, podemos comprobar una de las claves fundamentales a la hora de entender el turismo mundial en la globalización. Nos referimos a que se ha producido una contención de los precios, que, en determinados ámbitos o sectores del turismo, como los transportes, ha vislumbrado en realidad una disminución.

En primer lugar, debemos considerar los precios implícitos en la evolución de los ingresos generados por el turismo internacional. Así, teniendo en cuenta valores constantes de 2014, estos habrían logrado un moderado 2,9\% de promedio para el período 1980 a 2014,

5 Las exportaciones de bienes y servicios entre 1980 y el 2014 crecieron anualmente en un 5,5\% -valores corrientes de cada año-, según los datos que hemos recabado del International Monetary Fund, World Economic Outlook Database, April 2015. Es decir, el turismo ha contado con unas ratios de crecimiento superiores a las del conjunto de las exportaciones.

6 International Monetary Fund, World Economic Outlook Database, April 2015. 
inferior a la media registrada en el conjunto de la economía mundial ${ }^{7}$. En segundo lugar, en el año 1980 se registró un gasto medio por turista en valores corrientes de $375 \$$, mientras que en el 2014 se alcanzaron los $1.099 \$$. Es un crecimiento a priori importante. Ahora bien, si convertimos estos datos en valores constantes ( $\$$ de 2014) advertimos que el gasto por turista ha pasado realmente de los $910 \$$ en el año 1980 a los $1.099 \$$ del 2014 . Pero, es más, ya en 1989 se arribó a los 1.238\$, y en casi toda la década de los años 90 del siglo XX se superaron los mil dólares por turista. De todo ello deducimos que la contención cuando no disminución de los precios se ha constituido en un elemento esencial del actual modelo turístico mundial.

Gráfico 3

EVOLUCIÓN DEL GASTO MEDIO POR TURISTA INTERNACIONAL ENTRE 1980 Y EL 2014

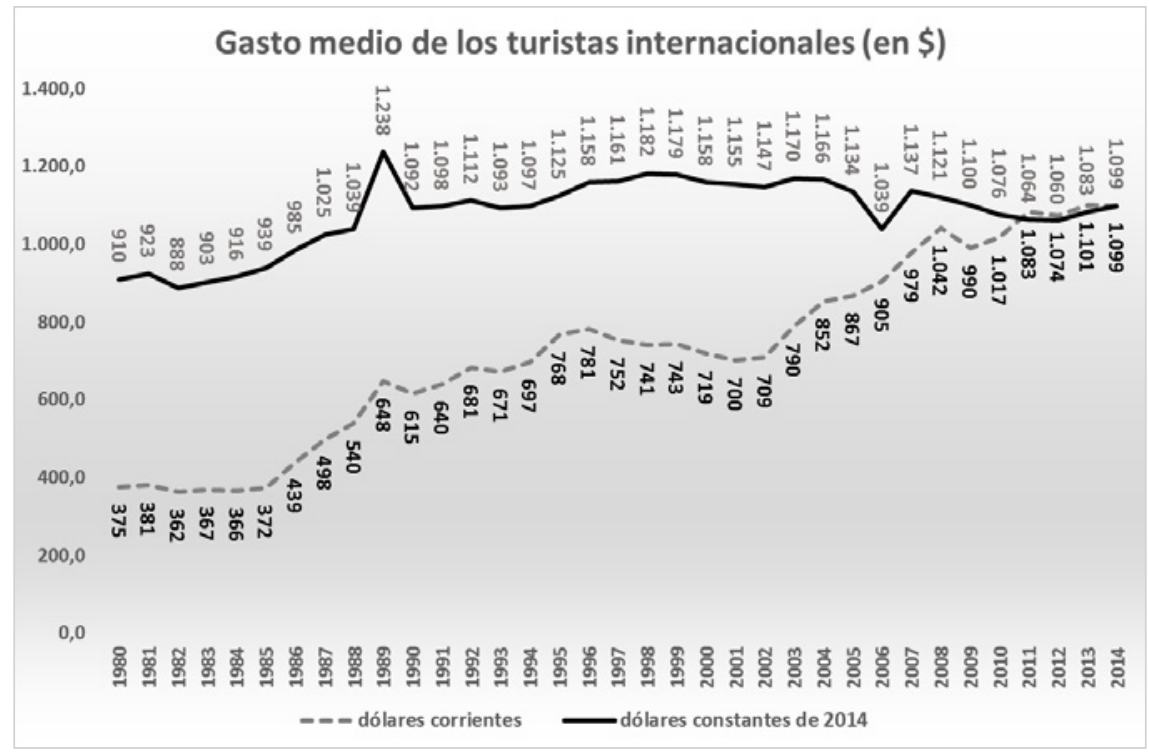

Fuente: Elaboración a partir de los datos de la OMT, del Fondo Monetario Internacional y del Banco Mundial.

\section{III.2. Cambios territoriales en los flujos turísticos: el turismo internacional}

Para analizar los grandes flujos turísticos, tanto nacionales como internacionales, hemos trabajado fundamentalmente con la base de datos del World Travel \& Tourism Council (WTTC), complementada con informaciones provenientes de las bases de la Organización Mundial del Turismo (OMT), del Banco Mundial (BM) y del Fondo Monetario Internacional (FMI) y, en determinados casos, hemos tenido en cuenta las estadísticas nacionales sobre turismo para intentar al máximo homogeneizar la información de partida.

7 Los precios implícitos en el PIB mundial entre 1980 y el 2014 crecieron de promedio un 3,1\% anual. También es significativo, que la tasa media de inflación (precios al consumidor) mundial se situase en igual período en un $12 \%$ anual. Estos datos los hemos obtenido del International Monetary Fund, World Economic Outlook Database, April 2015. 
La observación detenida de las cifras manifiesta fehacientemente los cambios producidos en la territorialización del turismo mundial, en estos años de globalización. La principal constatación que podemos argüir hace referencia a la complegización de las dinámicas espaciales del turismo, en consonancia con un modelo turístico concordante con las lógicas económicas, sociales, culturales e institucionales de la globalización del capitalismo contemporáneo. Junto ella hemos de señalar dos procesos más que tienen relevancia: de un lado, sigue constatándose un relativo predominio de los países más desarrollados en el turismo mundial; de otro, y no menos importante, han emergido con fuerza nuevos sistemas turísticos nacionales que aúnan un dinamismo turístico interno con una notable capacidad de captación de turistas extranjeros.

En el año 1980 los países más desarrollados (EEUU, Canadá, Europa Occidental, Israel, Japón, Corea del Sur, Taiwán, Hong Kong, Macao, Australia y Nueva Zelanda) concentraban el $66 \%$ de los turistas internacionales y un $73 \%$ de los ingresos que de ellos se derivaron, mientras que en el año 2014 ese predominio se ha reducido: ahora captaban el 51\% de los turistas internacionales y agrupaban el $63 \%$ del gasto que producían.

Tabla 1

CAMBIOS EN LA REGIONALIZACIÓN DEL TURISMO INTERNACIONAL EN EL MUNDO 1980 A 2014

\begin{tabular}{|c|c|c|c|c|}
\hline \multirow[t]{2}{*}{ regiones turísticas del mundo } & \multicolumn{2}{|c|}{$\begin{array}{l}\text { número de turistas } \\
\text { internacionales (\%) }\end{array}$} & \multicolumn{2}{|c|}{$\begin{array}{l}\text { ingresos por turismo } \\
\text { internacional }(\%)^{*}\end{array}$} \\
\hline & 1980 & 2014 & 1980 & 2014 \\
\hline Caribe & 2,38 & 1,90 & 3,11 & 1,86 \\
\hline Rusia y Europa del Este & 12,61 & 11,42 & 3,19 & 6,20 \\
\hline India y Centro y Sur de Asia & 0,81 & 1,95 & 1,31 & 2,11 \\
\hline América Latina & 6,62 & 5,92 & 6,32 & 4,16 \\
\hline Norte de África y Oriente Medio & 6,38 & 11,08 & 7,78 & 8,44 \\
\hline Estados Unidos y Canadá & 12,08 & 8,00 & 9,51 & 5,11 \\
\hline China, Japón y Este de Asia & 3,24 & 11,91 & 4,13 & 15,24 \\
\hline Australia y Oceanía & 0,71 & 1,07 & 1,72 & 3,08 \\
\hline Sudeste de Asia & 2,94 & 8,48 & 2,85 & 7,75 \\
\hline África Subsahariana & 1,59 & 3,16 & 2,44 & 2,16 \\
\hline Europa Occidental & 50,64 & 35,12 & 57,66 & 43,89 \\
\hline Mundo & 100,00 & 100,00 & 100,00 & 100,00 \\
\hline $\begin{array}{l}\text { total mundial (el número de turistas en } \\
\text { millones de personas, los ingresos en } \\
\text { millones de \$ corrientes) }\end{array}$ & 292.939 & 1.141 .205 & 132.806 & 1.448 .813 \\
\hline
\end{tabular}

Fuente: Elaboración a partir de los datos de la OMT para el año 1980, completado con datos nacionales, y de las cifras del WTTC y de la OMT para el año 2014, completado igualmente con valores obtenidos directamente de organismos oficiales de determinados países de los cuáles ni OMT ni WTTC ofrecen información.

*Los ingresos por turismo internacional incluyen el gasto personal y el gasto en transportes.

Probablemente, en este contexto el cambio de mayor repercusión ha sido la pérdida relativa del papel central en el turismo internacional de Europa Occidental. En efecto, si en el año 1980 Europa Occidental sumaba el 51\% de los turistas extranjeros a nivel mundial, en el año 2014 esa proporción había disminuido hasta el 35\%. América del Norte (EEUU y 
Canadá) también ha contemplado una reducción considerable de su rol: del 12\% al 5\%. Esto no quiere decir que no hayan sido espacios turísticos dinámicos, sino que otros lo han sido con mucho mayor ímpeto y fortaleza. Este sería el caso de China, Japón y el Este de Asia (Corea del Sur, Taiwán, Hong Kong y Macao), que en este período pasa de un modesto 3\% del turismo internacional a un $12 \%$, quintuplicando su índice en esta época. Como igualmente esta expansión se ha registrado en el Sudeste de Asia (Tailandia, Vietnam, Malasia, Indonesia...), que asciende desde el 2,9\% al 8,5\% del contingente de turistas captados que se movieron de país a país. En términos de ingresos por el turismo internacional la evolución ha sido lógicamente muy similar, si bien el mayor gasto per cápita de los turistas que visitan los países más desarrollados permite que éstos mantengan un papel ligeramente superior.

Estas trayectorias regionales se traducen en dinámicas nacionales que muestran esta doble cara del modelo turístico globalizado: de un lado, la consolidación del turismo en los países desarrollados y, de otro, la emergencia de nuevos espacios con singular capacidad de atraer turistas internacionales. Así, por ejemplo, en el primer caso situamos a Francia que, si en 1980 recibió 30,1 millones de turistas extranjeros, en el 2014 esa cifra ascendía 83,7 millones, mientras que en idéntico período los EEUU pasaban de 22,5 millones a 74,8 millones y España de 22,4 millones a 65 millones. En el segundo caso, tenemos países como China que, si bien contó con la visita de 3,5 millones de turistas foráneos en 1980, en el año 2014 arribó a los 55,6 millones; también podemos destacar a Turquía que pasa de sólo 921.000 turistas de otros países a 39,8 millones en el mismo lapso de tiempo. Una evolución que se repite en Malasia que pasa de 2,1 millones a 27,4 millones de turistas extranjeros, o en Tailandia que va desde los 1,9 millones a los 24,8 millones, Hong Kong que lo hace desde los 1,7 millones a los 27,8 millones, Macao que va desde los 550.000 a los 14,6 millones o en Rusia que pasa de 4,9 millones a 29,8 millones. Casos también paradigmáticos son los de Vietnam que de apenas 50.000 turistas extranjeros en el año 1980 pasa a 7,9 millones en el 2014, o los Emiratos Árabes Unidos que de 300.000 asciende a los 13,1 millones. Los ingresos por este turismo internacional muestran unas dinámicas similares.

\section{III.3. Cambios territoriales en los flujos turísticos: el turismo doméstico y el total}

Sin embargo, el turismo internacional (el que un ciudadano realiza en un país extranjero) es sólo uno de los grandes flujos que configuran el modelo turístico. En realidad, el turismo doméstico (el que los propios nacionales realizan en su país) tiene a nivel global un protagonismo fundamental en términos de movimiento de personas y de ingresos/gastos que generan. Dado que no existe una estadística detallada para todos los países sobre movimiento interno de turistas, debemos utilizar básicamente el valor de los ingresos que generan y que se estiman cada año y para la mayoría de países por el WTTC $^{8}$, y circunscribirlo al período 1990 a 2014 -para los primeros siete años de la década de los ochenta no hay estimaciones-.

8 La base de datos del World Travel \& Tourism Council incluye datos de 186 países, por lo tanto, no recoge información sobre una cuarentena de países y territorios, si bien aporta información sobre más del $95 \%$ del valor de la actividad turística mundial, por lo que su grado de representatividad es muy elevado y de un muy notable interés para los investigadores y responsables de las políticas turísticas. Esta fuente, para determinados países, muestra valores diferentes a los que a su vez estima la Organización Mundial del Turismo. En estos casos, hemos completado la información directamente buscando las estadísticas turísticas en los organismos oficiales de dichos países. 
A partir de esta fuente podemos deducir que el modelo turístico mundial (sumando el de origen doméstico con el de origen extranjero) generó en 1990 unos ingresos directos de 1.365.100 millones de dólares a precios corrientes, que en el año 2014 ascendieron a los 5.025.900 millones. Los flujos turísticos internos de cada país alcanzaron un valor de 1.062.500 millones de \$ en 1990 y de 3.642.000 millones en el año 2014, mientras que los flujos internacionales representaron unos ingresos de 302.600 millones de $\$$ en 1990 y de 1.383.900 millones en 2014. Esto supone que en la primera fecha analizada el turismo doméstico concentraba el $78 \%$ de los ingresos totales obtenidos por el turismo en el mundo, proporción que se redujo relativamente hasta el $72 \%$ registrado en la segunda fecha. La explicación de esta dispar evolución la encontramos en los distintos ritmos de crecimiento, puesto que si contemplamos estos valores en valores constantes comprobamos que el turismo global creció a un promedio anual del 3,8\% entre 1990 y el 2014, si bien el turismo internacional lo hizo a un ritmo del 5,9\% mientras el turismo doméstico lo hacía a un 3,2\%.

Tabla 2

DISTRIBUCIÓN REGIONAL DEL TURISMO MUNDIAL Y DEL TURISMO DOMÉSTICO, 1990 Y 2014

\begin{tabular}{|c|c|c|c|c|}
\hline \multirow[t]{2}{*}{ grandes regiones turísticas } & \multicolumn{2}{|c|}{$\begin{array}{l}\text { Porcentaje del total ingresos por } \\
\text { turismo del mundo (turismo } \\
\text { extranjero+turismo doméstico) }\end{array}$} & \multicolumn{2}{|c|}{$\begin{array}{l}\text { Porcentaje sobre el turismo } \\
\text { doméstico mundial }\end{array}$} \\
\hline & 1990 & 2014 & 1990 & 2014 \\
\hline Caribe & 0,96 & 0,77 & 0,31 & 0,31 \\
\hline Rusia y Europa del Este & 4,08 & 3,78 & 3,85 & 2,79 \\
\hline India y Centro y Sur de Asia & 1,49 & 2,86 & 1,44 & 3,13 \\
\hline América Latina & 8,43 & 8,52 & 9,20 & 10,12 \\
\hline Norte de África y Oriente Medio & 3,83 & 5,19 & 3,22 & 3,64 \\
\hline Estados Unidos y Canadá & 20,62 & 19,79 & 21,70 & 21,53 \\
\hline China, Japón y Este de Asia & 12,64 & 21,41 & 14,64 & 23,44 \\
\hline Australia y Oceanía & 2,81 & 2,62 & 2,76 & 2,60 \\
\hline Sudeste de Asia & 2,26 & 4,36 & 1,46 & 2,94 \\
\hline África Subsahariana & 0,85 & 1,64 & 0,73 & 1,40 \\
\hline Europa Occidental & 42,03 & 29,07 & 40,71 & 28,11 \\
\hline Mundo & 100,00 & 100,00 & 100,00 & 100,00 \\
\hline total mundial (millones de \$ corrientes) & 1.365 .100 & 5.025 .945 & 1.062 .500 & 3.642 .087 \\
\hline
\end{tabular}

Fuente: Elaboración a partir de la base de datos de la WTTC, completada con datos de la OMT, el Banco Mundial y el Fondo Monetario Internacional. En algunos casos, hemos tenido en cuenta las cifras producidas por los organismos estadísticos de determinados países.

El turismo doméstico en el mundo, estrechamente ligado a los niveles de renta de la población de cada país y muy sensible a las coyunturas socioeconómicas ${ }^{9}$, muestra en la actualidad todavía un predominio del que se ubica en los países más desarrollados, si bien el

9 E igualmente relacionado con los niveles de formación y los patrones socioculturales de comportamiento, así como con la existencia y disponibilidad de infraestructuras de transportes. Es obvio que también tiene una incidencia significativa la propia existencia y valorización social de potenciales recursos naturales y socioculturales turísticos. 
protagonismo de estos se está reduciendo significativamente en los últimos años. En efecto, si en 1990 los países más desarrollados concentraban el 76\% de los ingresos obtenidos por el turismo doméstico, esa proporción había caído a un $60 \%$ en el 2014. Buena parte de esa disminución se encuentra en la trayectoria seguida por el turismo doméstico en Europa Occidental, muy afectado por el impacto de la reciente crisis económica sobre su población, puesto que ha visto un recorte de su papel a escala mundial en este tipo de turismo del $41 \%$ logrado en el año 1990 al 28\% del 2014. En cambio, otros espacios turísticos han mostrado un mayor dinamismo de su turismo interno. Especialmente significativo es el caso de la región de China, Japón y Este de Asia, que en el año 2014 ya concentraba algo más del 23\% de los ingresos por turismo interno, superando a América del Norte, por ejemplo. Dentro de esta región asiática destacaba con claridad la evolución seguida por la sociedad china, que si en 1990 gastó en hacer turismo en su país 43.900 millones de \$, en el 2014 superó los 566.000 millones. También han mostrado una evolución muy positiva regiones turísticas como la India y Centro y Sur de Asia, el Sudeste Asiático o el África Subsahariana.

La traslación de estos volúmenes de ingresos a valores constantes de 2014, nos permite reforzar los nuevos protagonismos en el turismo mundial. Así, mientras Europa Occidental solamente crecía a un ritmo del 1\% anual entre 1990 al 2014 en cuanto a los ingresos obtenidos por su turismo doméstico o que los EEUU y Canadá lo hacían a un 3,2\% -es cierto que ya partían en cifras muy importantes-, en cambio el India y el Centro y Sur de Asia lo hicieron a un $12 \%$ de promedio anual, el Sudeste de Asia y África Subsahariana a un nivel del $10 \%$ anual respectivamente, situándose después con una ratio más moderada América Latina y África del Norte y Oriente Medio al alcanzar un promedio en torno al 4\%. Estos disímiles comportamientos se muestran igualmente a escala de país, puesto que si bien Italia veía como su turismo doméstico aumentaba de media anual un 0,4\% entre 1990 y el 2014, Japón del 0,5\%, Gran Bretaña del 0,6\% o que Francia lo hacía a un 1,2\%, otros países como China registraron un espectacular promedio anual del 22,8\%, Turquía del 15,1\%, la India del $11,4 \%$ o México del 4,5\% ${ }^{10}$.

De la interacción en una región o país de este turismo doméstico con el turismo de realizan los ciudadanos extranjeros, resulta la actividad turística total que se desarrolla en cada espacio durante un tiempo determinado.

Como ya hemos señalado, en el mundo el conjunto de actividades turísticas en el año 2014 generó unos ingresos directos estimados en 5.025.900 millones de \$. De esta cifra, los

10 Los EEUU registraron en 1990 un total de 980 millones de viajes internos, que se incrementaron hasta los 2.088 millones del año 2014 (US Travel Association). En cambio, China pasó de 280 millones de viajes domésticos en 1990 a 3.262 millones en el 2014 (http://www.stats.gov.cn/ y Eijgelaar, Peeters y Piket, 2008). Es decir, si los EEUU contabilizaban casi cuatro veces más viajes internos que China en 1990, ahora este país supera notablemente al país americano. También en la India se ha producido una eclosión del turismo doméstico. En efecto, en 1990 solamente se estimaron en 67 millones los viajes internos de los ciudadanos indios, que fueron ya 220 millones en el año 2000 y que alcanzaron los 1.282 millones en el 2014 (www.statisca.com; Indian Tourism Statistics -diversos años-). No obstante, no podemos olvidar que la proporción de población que realiza un viaje turístico o más es significativamente superior en los EEUU que en China o en la India. Como información complementaria podemos indicar que los viajes domésticos turísticos en Francia han pasado de 146 millones en 1997 a 200 millones en el 2013, mientras en Gran Bretaña han ido desde los 87 millones a los 107 millones y en España de los 119 millones a los 122 millones de viajes. Los períodos, como vemos, no son comparables, pero sí es representativo de lo sucedido en estos países en términos del turismo que realizan sus propios conciudadanos (los datos proceden de la base de datos de EUROSTAT). 
países más desarrollados concentraron el 60,5\%, mientras que los países emergentes y los países en desarrollo sumaban el 39,5\% restante -en el año 1990 las proporciones eran del 75\% y del 25\% respectivamente-. La principal región turística sería Europa Occidental, que con unos ingresos de 1.461.500 millones de \$ equivalía al 29\% de la actividad turística mundial -si bien este papel preeminente, que ya era así desde el turismo de masas en los años 50 del siglo XX, se ha visto constreñido de forma significativa pues había llegado a equivaler al 42\% del total mundial en 1990-. A continuación, se situaba la región formada por China, Japón y el Este de Asia, que en el 2014 con los ingresos obtenidos por el turismo interno y externo ha superado la barrera del $21 \%$ del total, situándose por primera vez por encima de los EEUU y Canadá que agrupaban el $20 \%$ del valor económico producido por el turismo. A notable distancia se encuentra América Latina que aportaba el 8,5\% de la producción turística mundial, seguida del Sudeste de Asia con un 4,4\% y de Rusia y el Este de Europa 3,8\%. Por cierto, una región de renombre tan turístico como el Caribe, solamente generó en el año 2014 el 0,8\% de los ingresos mundiales del turismo.

La observación detenida de estos ingresos que produce el turismo, pero ahora a nivel nacional, que aúnan el turismo doméstico y el que generan los visitantes extranjeros, completa el análisis de las dinámicas territoriales turísticas, y muestra fehacientemente qué países lideran el turismo mundial, y cuáles han mostrado recientemente un mayor dinamismo.

Los Estados Unidos ocupaban en el año 2014 la primera posición, con un turismo que generó 940.400 millones de \$ de valor de su producción, que equivalían al 18,7\% del total mundial. En segundo lugar, destacaba China que de ser un país "cerrado a los extranjeros" y en el cual los propios chinos tenían notable dificultades de movilidad interna y externa a principios de la década de los ochenta, momento de inicio de la globalización, ha pasado a convertirse en la segunda potencia turística del planeta, sólo superada por los EEUU. China consiguió en el 2014 concentrar el 12,5\% de la actividad turística global, cuando en 1990 solamente suponía el 3,5\%. A partir de aquí encontramos a los grandes países turísticos tradicionales como Alemania, Gran Bretaña, Francia, Italia o España, países que sobre todo tienen un consumo turístico doméstico muy potente caso de Australia o Japón y, después, a países turísticos emergentes que en algunos casos a una importante capacidad de atraer turistas foráneos suma un creciente dinamismo del turismo interno ante la expansión del gasto turístico de sus clases medias y altas, como sería el caso de México, Brasil, India, Rusia, Turquía, y, en menor medida, de Indonesia y Tailandia. Un caso especial es el representado por Hong Kong y por Macao, ciudades que, con un estatus político espacial pertenecen a China, y que en los últimos años han alcanzado una consolidación de ciudades turísticas internacionales de primer orden -sumando turismo de negocios, a turismo ligado al ocio, las compras y al juego, muy dirigido a la población de China y de otros países asiáticos-.

Asimismo, es necesario destacar que el turismo está presente en prácticamente todos los países del planeta, pero, igualmente debemos resaltar el elevado grado de concentración territorial que manifiesta, puesto que los cinco primeros países controlaban prácticamente la mitad de la actividad turística mundial.

Por otra parte, las disímiles dinámicas que dibujan el turismo internacional y el turismo doméstico en la mayoría de países y que hemos esbozado, en las cuáles, además, cada uno desempeña un papel diferente, justifican los dispares ritmos de crecimiento que el turismo ha seguido en cada región turística o en cada país. La explicación última estriba en la conju- 
Tabla 3

PRINCIPALES PAISES TURÍSTICOS DEL MUNDO, 1990 Y 2014

\begin{tabular}{|c|c|c|c|c|}
\hline \multirow[b]{2}{*}{ países } & \multicolumn{2}{|c|}{$\begin{array}{c}\text { ingresos por turismo doméstico } \\
\text { y turismo internacional } \\
\text { (millones de \$) }\end{array}$} & \multicolumn{2}{|c|}{$\begin{array}{c}\text { ingresos por turismo doméstico } \\
\text { y turismo internacional }(\%)\end{array}$} \\
\hline & 1990 & 2014 & 1990 & 2014 \\
\hline EEUU & 261.349 & 940.436 & 19,15 & 18,71 \\
\hline China & 47.319 & 626.776 & 3,47 & 12,47 \\
\hline Alemania & 157.428 & 398.663 & 11,53 & 7,93 \\
\hline Gran Bretaña & 103.363 & 237.454 & 7,57 & 4,72 \\
\hline Japón & 97.588 & 226.254 & 7,15 & 4,50 \\
\hline Francia & 70.411 & 194.623 & 5,16 & 3,87 \\
\hline Italia & 76.998 & 161.921 & 5,64 & 3,22 \\
\hline España & 48.754 & 147.837 & 3,57 & 2,94 \\
\hline México & 39.680 & 146.616 & 2,91 & 2,92 \\
\hline Brasil & 47.699 & 137.504 & 3,49 & 2,74 \\
\hline India & 13.126 & 107.924 & 0,96 & 2,15 \\
\hline Australia & 29.241 & 100.790 & 2,14 & 2,01 \\
\hline Rusia & 24.266 & 78.475 & 1,78 & 1,56 \\
\hline Corea del Sur & 14.568 & 74.020 & 1,07 & 1,47 \\
\hline Turquía & 6.286 & 68.060 & 0,46 & 1,35 \\
\hline Tailandia & 8.074 & 57.695 & 0,59 & 1,15 \\
\hline Hong Kong, China & 6.225 & 57.137 & 0,46 & 1,14 \\
\hline Macao, China & 2.342 & 55.818 & 0,17 & 1,11 \\
\hline Canadá & 20.147 & 54.434 & 1,48 & 1,08 \\
\hline Indonesia & 9.574 & 47.875 & 0,70 & 0,95 \\
\hline Austria & 20.113 & 44.773 & 1,47 & 0,89 \\
\hline resto del mundo & 260.534 & 1.060 .860 & 19,09 & 21,11 \\
\hline total mundial & 1.365 .087 & 5.025 .945 & 100,00 & 100,00 \\
\hline
\end{tabular}

Fuente: Elaboración a partir de la base de datos de la WTTC, completada con datos de la OMT, el Banco Mundial y el Fondo Monetario Internacional. En algunos casos, hemos tenido en cuenta las cifras producidas por los organismos estadísticos de determinados países.

gación de múltiples factores globales y nacionales y que hacen referencia a la evolución de la economía y de los niveles de renta (y por tanto a la capacidad de consumo turístico), a la situación política e institucional, a la dotación de infraestructuras de alojamiento, restauración, transporte y ocio, a las políticas turísticas que se desarrollan, a como se posicionan los diversos territorios en las redes sociales y en los grandes medios de comunicación de masas, y al valor estratégico que determinados recursos turísticos territoriales -naturales o culturalescumplen para los grandes grupos empresariales del sector nacionales e internacionales, por citar aquellos más relevantes. En este sentido, el turismo mundial habría crecido entre 1990 y el 2014, en valores constantes de 2014 y teniendo en cuenta los ingresos directos obtenidos, a un ritmo del 3,8\% anual. De un lado, tendríamos a Europa Occidental que se situaría con un $1,4 \%$ de promedio y el Caribe con un $2 \%$, mientras que Rusia y la Europa del Este, América 
Latina y EEUU/Canadá lo habrían hecho con valores entre el 3\% y el $4 \%$ anuales, por tanto, en torno a la media mundial. De otro lado, tenemos regiones como la India y Centro y Sur de Asia, el Sudeste Asiático o el África Subsahariana que han vislumbrado una evolución muy vigorosa con una ratio anual media del $11 \%$. Esta misma aproximación efectuada a escala de cada país, aún muestra con más claridad estas tendencias. Por una parte, países con sistemas turísticos consolidados han contado con valores muy moderados: Italia sólo creció un $0,4 \%$ de promedio anual entre 1990 a 2014, Austria a un 0,7\%, Gran Bretaña a un 0,8\%, Japón a un $0,9 \%$, Alemania a un 1,3\%, Francia a un 1,8\% y España a un 2,4\%. Los Estados Unidos habrían alcanzado un valor más elevado, al situarse en un 3,7\% de media anual. Por otra parte, China alcanzó una media anual del 24,6\% de incremento de los ingresos globales por turismo, Turquía del 19,3\%, Hong Kong con un 15,8\%, India del 13,7\% y Indonesia con un $6,7 \%$. Un caso especial por su particularidad es el de Macao, que registró un índice anual medio del $45,8 \%$. Es evidente que estos niveles tan elevados han comportado una expansión de los espacios internos "turístificados" en estas naciones, al mismo tiempo, que se desarrollaban exponencialmente las estructuras de alojamiento, restauración y ocio. Cabe anotar que, contrariamente, los grandes países latinoamericanos han mostrado unos valores relativamente bajos, así, por ejemplo, México progresó a un nivel del 3,9\% y Brasil del $2,1 \%$, muy lastrados por las inestables coyunturas económicas y la persistencia de una fuerte desigualdad social que deriva en la exclusión de una parte de la población de la posibilidad de consumir productos turísticos.

\section{III.4. Cambios territoriales en los flujos turísticos: consumo turístico}

El turismo es actividad productiva y, al mismo tiempo, es consumo. Este último está estrechamente relacionado con la renta media de las familias, con la fortaleza o debilidad del estado del bienestar, y con la presencia o no de niveles significativos de desigualdad y de exclusión social. Evidentemente, también está muy condicionado por la propia magnitud de sus efectivos demográficos. Consideramos, en este sentido, que valorar la capacidad de consumo turístico y cómo esta se materializa, nos ayuda a completar esta visión de conjunto del turismo globalizado que estamos realizando, y percibir los cambios territoriales que la vertebran.

En el año 1990, de todo el consumo turístico que hicieron los residentes de cada país tanto dentro de su nación como fuera de ella, un significativo $42 \%$ tuvo su origen en Europa Occidental, seguido del $21 \%$ generado por los Estados Unidos y Canadá. Dos decenios y medio después, Europa Occidental sigue manteniendo una posición preeminente, pero ha disminuido claramente su participación en el total mundial hasta representar, con datos del año 2014, casi un 30\%. Por su parte, los Estados Unidos y Canadá han mostrado igualmente una disminución de su papel, aunque en menor medida que la región europea, situándose ahora en el casi $20 \%$ del total. En cambio, la región que configuran China, Japón y el Este de Asia ha pasado de representar el 14\% al 22\% durante este período, situándose, así, como la segunda región generadora de consumo turístico del mundo, sólo superada de momento por Europa Occidental. A continuación, se encontraba América Latina que aportaba el 9\% del consumo turístico mundial del año 2014, un porcentaje prácticamente similar al obtenido en el año 1990. Ya a mayor distancia se ubicaban el Norte de África y Oriente Medio, Rusia y Europa del Este y, finalmente, el Sudeste Asiático. 
Tabla 4

PAPEL REGIONAL EN EL CONSUMO TURÍSTICO TOTAL: DOMÉSTICO Y EXTRANJERO

\begin{tabular}{|c|c|c|c|c|c|c|}
\hline \multirow[t]{2}{*}{ grandes regiones turísticas } & \multicolumn{2}{|c|}{$\begin{array}{c}\text { consumo turístico de los } \\
\text { residentes dentro y fuera } \\
\text { de su pais }(\%)\end{array}$} & \multicolumn{2}{|c|}{$\begin{array}{c}\text { consumo turístico de los } \\
\text { residentes fuera de su país } \\
(\%)\end{array}$} & \multicolumn{2}{|c|}{$\begin{array}{c}\text { consumo turístico de los } \\
\text { residentes dentro de su } \\
\text { país (\%) } \\
\end{array}$} \\
\hline & 1990 & 2014 & 1990 & 2014 & 1990 & 2014 \\
\hline Caribe & 0,49 & 0,45 & 1,08 & 0,87 & 0,32 & 0,31 \\
\hline Rusia y Europa del Este & 4,54 & 4,05 & 6,96 & 7,66 & 3,85 & 2,79 \\
\hline India y Centro y Sur de Asia & 1,34 & 2,78 & 1,01 & 1,76 & 1,43 & 3,13 \\
\hline América Latina & 8,49 & 8,91 & 6,01 & 5,45 & 9,20 & 10,12 \\
\hline Norte de África y Oriente Medio & 3,83 & 4,71 & 6,00 & 7,79 & 3,22 & 3,64 \\
\hline Estados Unidos y Canadá & 20,91 & 19,63 & 18,17 & 14,15 & 21,69 & 21,53 \\
\hline China, Japón y Este de Asia & 13,53 & 21,82 & 9,67 & 17,16 & 14,63 & 23,44 \\
\hline Australia y Oceanía & 2,84 & 2,72 & 3,13 & 3,05 & 2,76 & 2,60 \\
\hline Sudeste de Asia & 1,52 & 3,52 & 1,74 & 5,21 & 1,46 & 2,94 \\
\hline África Subsahariana & 0,89 & 1,57 & 1,48 & 2,06 & 0,73 & 1,40 \\
\hline Europa Occidental & 41,60 & 29,85 & 44,75 & 34,85 & 40,70 & 28,11 \\
\hline Mundo & 100,00 & 100,00 & 100,00 & 100,00 & 100,00 & 100,00 \\
\hline total mundial (millones de $\$$ corrientes) & 1.366 .021 & 4.908 .461 & 303.360 & 1.266 .520 & 1.062 .496 & 3.642 .087 \\
\hline
\end{tabular}

Fuente: Elaboración a partir de la base de datos de la WTTC, completada con datos de la OMT, el Banco Mundial y el Fondo Monetario Internacional. En algunos casos, hemos tenido en cuenta las cifras producidas por los organismos estadísticos de determinados países.

Cuando ese consumo turístico se diferencia entre el que se efectúa dentro de las fronteras nacionales de aquél que se realiza en el extranjero, podemos observar divergencias territoriales destacables. De nuevo aquí, tanto los niveles de renta familiar generales, como la presencia y amplitud de las clases medias, son factores explicativos fundamentales. Efectivamente, si observamos globalmente de todo el consumo turístico realizado en el mundo, las tres cuartas partes se desarrolló dentro de las fronteras de cada país por sus residentes, y solo la cuarta parte se efectuó en el extranjero. Pues bien, de los recursos utilizados para consumir actividades turísticas en el extranjero, Europa Occidental generó el $35 \%$, ocupando la primera posición a escala de las grandes áreas geoturísticas, aunque es una proporción inferior a la registrada en 1990, duplica la de su inmediata seguidora que es la región de China, Japón y el Este de Asia que aportó el equivalente al 17\% de los recursos consumidos en acciones y actividades turísticas. Aquí debemos destacar, especialmente, el papel desempeñado por la expansión espectacular del turismo que los ciudadanos chinos realizan en el exterior: si en 1990 solamente salieron 620.000 chinos a hacer turismo fuera de su país, en el 2014 fueron 100 millones; en términos económicos esto supone que de un gasto turístico en el exterior de apenas 247 millones de $\$$ en 1990 hemos pasado a 127.000 millones en el año $2014^{11}$. Después de esta región encontramos a los Estados Unidos y

11 Entre el año 2000 y el 2014 el consumo turístico en el extranjero de China creció como promedio anual en un 44\% -si lo medimos en valores constantes del 2014-, en Brasil ascendió ese indicador al 14\%, en Turquía un 7\%, en México del 3\%, mientras en España se consiguió el 4\%, situándose con valores muy bajos Francia con una media anual del 1,4\% y en los EEUU del 1,3\%, mientras que Alemania lo hacía a un modesto 0,6\% anual, Gran Bretaña del $0,7 \%$ y Italia con un $0,2 \%$. Es significativo que Japón registrase en valores constantes un decrecimiento de su consumo turístico en el exterior de un 3,3\% anual en este período. 
Canadá que fueron el origen del 14\% del gasto turístico en el extranjero. A mayor distancia estaban Rusia y la Europa del Este de un lado, y el Norte de África y Oriente Medio del otro, con un valor entre el $7 \%$ y el $8 \%$.

Gráfico 4

CONSUMO TURISTICO PER CÁPITA Y DESIGUALDADES REGIONALES, AÑO 2014

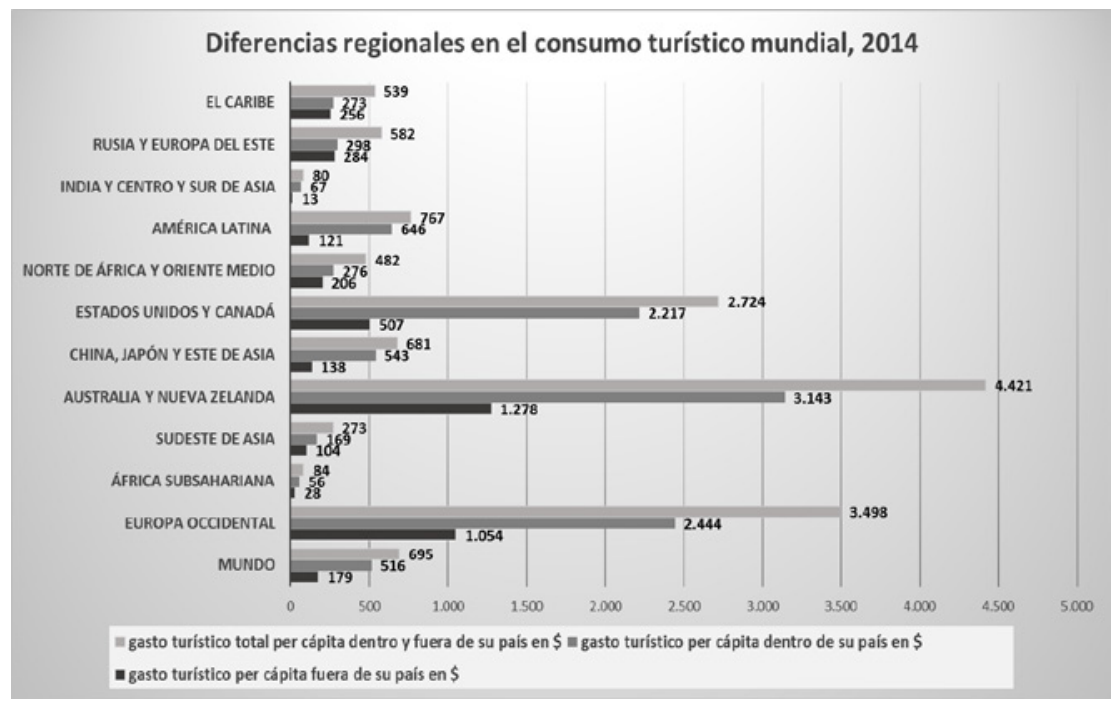

Fuente: Elaboración a partir de la base de datos de la WTTC, completada con datos de la OMT, el Banco Mundial y el Fondo Monetario Internacional. En algunos casos, hemos tenido en cuenta las cifras producidas por los organismos estadísticos de determinados países. Los datos de población utilizados proceden de la estimación de los habitantes de cada país para el mes de julio de 2014 que ha realizado POPIN/ONU -www.un.org/popin/-, y las que aporta el Population Reference Bureau -www.prb.org-.

El gasto turístico que se realiza en cada país por sus propios residentes, ya lo hemos comentado cuando hablábamos del turismo doméstico, en todo caso resaltar que el peso de Europa Occidental disminuye en relación al que acabamos de señalar, en beneficio fundamentalmente de China, Japón y Este de Asia y de los Estados Unidos y Canadá.

Este creciente papel de países emergentes turísticamente hablando, debe ser relativamente matizado, porque buena parte de ellos muestran como la mayoría de sus conciudadanos están excluidos de la posibilidad real de consumo turístico. Un buen indicador de esta situación lo encontramos en relacionar el volumen total de consumo turístico que se genera en una sociedad con su número de habitantes. En el año 2014 el consumo turístico total mundial fue de 695 \$ per cápita, sin embargo, en la región de la India, Centro y Sur de Asia apenas se alcanzaron los 80 por habitante y los 84 \$ en el África Subsahariana. En cambio, en Australia y Oceanía se llegó a los 4.421 \$, siete veces más que le media mundial y cincuenta y cinco veces más que el indicador de la India, Centro y Sur de Asia ${ }^{12}$-estas

12 Noruega contaba con un consumo turístico per cápita de 6.874 \$ (valor total del consumo turístico de los residentes fuera y dentro del país dividido por el número de habitantes) mientras que en la República del Congo sus 
disparidades se acrecientan cuando se habla sólo de consumo turístico en el extranjero-. Con valores también elevados se encontraban Europa Occidental que contaban con un consumo turístico per cápita de 3.498 \$ y los Estados Unidos y Canadá que consiguieron los 2.724 \$. Excepto América Latina, el resto de grandes regiones turísticas tenía una media inferior al indicador mundial.

\section{A MODO DE CONCLUSIÓN}

El turismo se ha globalizado y, sin duda, la globalización del capitalismo contemporáneo ha transformado profundamente el modelo turístico. Las dos aseveraciones son ciertas, y están estrechamente entrelazadas.

El turismo como conjunto de actividades económicas y laborales y como fenómeno sociocultural ha expansionado su radio de presencia a la globalidad del planeta. Las cifras, que aquí hemos expuesto, sobre el movimiento de viajeros y sobre los ingresos que éstos generan (o visto de otra forma, sobre el valor económico del consumo turístico que efectúan), son cada vez mayores y, además, en términos relativos han mostrado un dinamismo superior al de la propia economía mundial. A esta potencialidad del turismo se le une el papel que puede desempeñar como instrumento estratégico de desarrollo territorial, lo que ha supuesto que muchas administraciones públicas nacionales, regionales y locales, pero también numerosos organismos internacionales, hayan impulsado programas, planes y acciones que promueven el turismo, retroalimentando su expansión.

Al mismo tiempo, estas tres postreras décadas han vislumbrado los múltiples impactos de la globalización capitalista sobre las actividades turísticas, que han sido de tal calibre que han acabado transformándola. Así, las lógicas organizativas y locacionales que sustentan la globalización y la reestructuración del capitalismo actual, han sido los motores que han estimulado los intensos cambios desarrollados en el sistema turístico internacional y en los sistemas turísticos nacionales, regionales y locales, con grados y formas diversas que han respondido tanto al propio nivel de desarrollo de las formación social de la cual forman parte, como al impacto de los intereses de las grandes empresas turísticas internacionales. De esta forma, se ha fraguado un nuevo modelo turismo global concordante con el estadio de desarrollo del capitalismo actual, en el cual conviven formas que predominaban en el sistema turístico mundial que se configuró desde los años 50 a los 80 del siglo XX, con otras formas diferentes de organización, comercialización y consumo de las actividades turísticas y con otras lógicas espaciales de presencia de las actividades turísticas en el territorio.

Desde el punto de vista tanto de los grandes flujos turísticos como de los flujos locales, podemos destacar dos características fundamentales del nuevo modelo turístico. En primer lugar, se está configurando una lógica espacial turística compleja, en la que se desarrollan al mismo tiempo procesos de concentración territorial, de diseminación de esta actividad por casi todo el planeta, y de emersión en determinados casos de nuevos espacios turísticos que se consolidan con rapidez y alcanzan una notable dimensión. En segundo lugar, la aparición

ciudadanos solamente pudieron gastar en turismos (dentro y fuera del país) 8 \$ al año. Si sólo hablamos de consumo turístico en el extranjero las diferencias se hacen más amplias, puesto que por ejemplo Kuwait obtuvo a 5.205 o Luxemburgo de 4.586 \$, mientras que, en el otro fiel de la balanza, en la República del Congo solamente se gastó en hacer turismo en el extranjero una media de 1,5 \$ o de 0,9 \$ en Birmania. 
o reforzamiento de su valorización social de nuevas tipologías turísticas más allá del turismo de sol y playa y del de nieve y deportes de invierno -turismos de masas crecientemente segmentizados-, han propiciado que territorios (sea un país, una región o una localidad) que hasta ahora no participaban de los grandes flujos turísticos, en este momento estén presentes en ellos y, en algún caso, lleguen a ser protagonistas de los mismos. Estos procesos complejos se han visto promovidos, en buena medida, por los intereses de las grandes empresas de los diversos sectores que configuran el turismo; y, a su vez, se han visto posibilitados por el abaratamiento de los medios de transporte, por la desregulación de las normativas laborales en muchos países, y por la eclosión del acceso a la información turísticas de cualquier lugar del planeta a través de las nuevas tecnologías de la información y la comunicación.

Este modelo turístico, asimismo, se caracteriza porque una de sus estrategias esenciales de competitividad radica en la contención de los precios o su disminución en términos reales, lo que a su vez presiona considerablemente a la existencia de salarios bajos en el sector.

En definitiva, la globalización en estos decenios ha evidenciado la significativa vulnerabilidad del turismo a la coyuntura socioeconómica y política internacional -o nacional o regional según los casos-. Paradójicamente, al mismo tiempo, el turismo globalizado ha manifestado una notable capacidad de adaptación, basada, sobre todo, en que se desarrolla en su seno una "reinvención permanente" de nuevos productos y la "venta" de nuevos territorios turísticos acompañados de motivaciones, estructuras y dinámicas comerciales y empresariales cada vez más diversas.

\section{BIBLIOGRAFÍA}

ADDA, J. (2004): La mondialisation de l'économie. Editions. París, La Découverte.

AMIN, S. (2001): Capitalismo, imperialismo y mundialización. Buenos Aires, CLACSO.

ANTHONY, R. y SHARPLAY, J. (2009): Tourism development and the environment: beyond sustainability? (Tourism, Environment and Development). AdbingtonOxfordshire, Earthscan.

ANTÓN, S. y DURO, J. (2009): Competitividad y sistemas de innovación territorial en el turismo. Working Papers Innova 1. Tarragona, URV-Diputació de Tarragona.

BAUMAN, Z. (2002): La globalización: consecuencias humanas. México, FCE.

ASHELEY, C. y MICHEL, J. (2010): Tourism and poverty reduction: pathways to prosperity. Londres, Earthscan.

BAYLIS, J. y SMITH, S. (2005): The globalization of world politics. Oxford: Oxford University Press.

BERVEJILLO, F. (1996): Territorios en la globalización. Cambio global y estrategias de desarrollo territorial. ILPES, Documento 96/34. Montevideo.

BIANCHI, R. (2002): «Towards a new polical economy of global tourism», en Sharplay, R. y Telfa, D. (Ed.), Tourism and development: concepts and issues. Channel View, Clevedon, 265-299.

BOLTANSKI, L. y CHIAPELLO, E. (2002): El nuevo espíritu del capitalismo. Madrid: Akal.

CASTELlS, M. y HIMANEN, P. (Ed.) (2014): Reconceptualizing Development in the Global Information Age. Oxford. Oxford University. 
CÓRDOBA, J. y GARCÍA, A. (2003): «Turismo, globalización y medio ambiente en el Caribe mexicano». Investigaciones Geográficas, nº 52, 117-136.

EIJGELAAR, E.; PEETERS, P. y PIKET, P. (2008): «Domestic and International Tourism in a Globalized World», Research in Progress Paper presentado a The International Conference "Ever the twain shall meet- relating international and domestic tourism" del Research Committee RC50 International Tourism, International Sociological Association, Jaipur, Rajasthan, India, noviembre, 24-26.

FAYÓS SOLÀ, E. (1994): «Competitividad y calidad en la nueva era del turismo». Estudios Turísticos, $\mathrm{n}^{\circ}$ 123, 5-10.

FAYÓS SOLÁ, E. (2004): «Política turística en la era de la globalización». Mediterráneo Económico, $\mathrm{n}^{\circ}$ 5, 215-232.

GIDDENS, A. (1991): Modernity and Self-Identity: Self and Society in the Late Modern Age. Standford, Standford University Press.

HARVEY, D. (2007): Espacios del capital. Hacia una geografía crítica. Madrid, Akal.

HASSAN, S.S. (2000), «Determinants of market competitiveness in an environmentally sustainable tourism industry». Journal of Travel Research vol. 38, $\mathrm{n}^{\circ}$ 3, 239-245.

HELD, D. y MCGREW, A. (Ed.) (2004): The global transformations reader. An introduction to the globalization debate. Oxford, Blackwell Publishing.

HUNTER, C. (1997): «Sustainable Tourism as an Adaptative Paradigm». Annals of Tourism Research, vol.14, $\mathrm{n}^{\circ}$ 4, 850-867.

IANI, O. (1999): Teorias da gloablização. Río de Janerio, Civilização Brasileria.

IBÁÑEZ PÉREZ, R.M. (2011): «Diagnóstico de la calidad y competitividad del sector turístico en México». Cuadernos de Turismo n 28, 121-143.

IOANNIDES, D. y DEBBAGE, K. (1998): «New-fordism and flexible specialization in the travel industry», en IOANNIDES, D; DEBBAGE (Ed.), The economic Geography of the tourist industry. Londres, Routledge, 99-122.

KELLER, P. (1996): Globalization and tourism. St. Gallen, AIEST vol. 38.

KELLER, P. (2009): Global financial and economic crisis: what are the implications for world tourism. Madrid, OMT.

KELLER, P. y BIERGER, T.H. (Ed.) (2011): Tourism development after the crisis. Global imbalances, poverty alleviation. Göttingen: Enrich Schmidt Verlag.

LICKORISH, L. y JENKINS, C.L. (2000): Una introducción al turismo. Madrid: Editorial Síntesis.

LÓPEZ PALOMEQUE, F. (1999): «Política turística en el escenario de cambio turístico». Boletín de la AGE núm.28, 23-28.

LÓPEZ PALOMEQUE, F. y CÁNOVES, G. (Ed.) (2014): Turismo y territorio. Innovación, renovación y desafíos. Valencia, Colección Crónica, Tirant Humanidades.

MACHIAVELLI, A. (2001): «Tourist destinations as integrated systems». Tourism Review, vol. 56, $\mathrm{n}^{\circ}$ 3-4, 6-11.

MARRERO, J.R. y SANTANA, M.A. (2008): «Competitividad y calidad en los destinos turísticos de sol y playa. El caso de las Islas Canarias». Cuaderno de Turismo, $\mathrm{n}^{\circ} 22$, 123-143. 
MONTANARI, M.G. et al. (2013): «Um estudo sobre a relação entre competitividade no setor de turismo e o desenvolvimento dos países». Revista de Globalización, Competitividad y Gobernabilidad, vol. 7, $\mathrm{n}^{\mathrm{o}} 2,56-67$.

MPOFU, T.P.Z. (2009): «An assessment of the impact of tourism globalization in Africa». Journal of Business and Administative Studies, vol. 1, n 2, 1-19.

MUÑOZ, A.I.; FUENTES, L. y FAYOS-SOLÀ, E. (2012): «El Turismo como instrumento de desarrollo: una visión alternativa desde factores humanos, sociales e institucionales». Pasos. Revista de Turismo y Patrimonio Cultural, vol. 10, n 5, 437-449.

NORBERG, J. (2001): En defensa del capitalismo global. Madrid, Unión Editorial.

OMT (2007): Cambio climático y turismo. Responder a los retos mundiales. Madrid.

OMT (2013): Cambio demográfico y turismo. Madrid.

OMT (2013): Domestic Tourism in Asia and the Pacific. Madrid.

OMT (2013): El turismo como inductor del desarrollo, de la inclusión social y de la integración regional. Madrid.

OMT (2015): Tourism and the Sustainable Development Goals. Madrid.

OMT (2015): World Tourism Barometer and Statistical Annex, August 2015. Madrid.

OMT (2017): Tourism Highlights, 2017 Edition, Madrid.

OMT/ILO (2013): Economic crisis, international tourism decline and its impact on the poor. Madrid.

SANTOS, M. (2006): «Los espacios de la globalización». Anales de Geografía de la Universidad Complutense, $\mathrm{n}^{\circ} 13,69-77$.

STIGLITZ, J.E. (2002): El malestar en la globalización. Madrid, Editorial Taurus.

VÁZQUEZ BARQUERO, A. (2005): Las nuevas fuerzas del desarrollo. Barcelona, Antoni Bosch Editor.

VERA, J.F. (COORD.) LÓPEZ, F.; MARCHENA, M.J.; ANTÓN, S. (1997): Análisis territorial del turismo. Barcelona: Ariel.

VERA, J.F.; BAÑOS, C.J. (2010): «Renovación y reestructuración de los destinos turísticos consolidados del litoral: las prácticas recreativas en la evolución del espacio turístico». Boletín de la Asociación de Geógrafos Españoles, nº53, 329-353.

WAHAB, E.; COOPER, CH. (Ed.) (2001): Tourism in the age of globalization. Londres, Routledge. 
